\title{
Science and Technology and their Role in Human Health in Developing Countries
}

\author{
Eloi S Garcia
}

Fundação Oswaldo Cruz, Av. Brasil 4365, 21045-900 Rio de Janeiro, RJ, Brasil

Key words: science - technology - human health - developing countries

\begin{abstract}
Beginning of a new century. Technological innovation is the propelling force of capitalism. The investments in research and development become increasingly decisive for the success of a nation. Innovations are introduced fast and intensively to the markets. The systems involved with national development gain more and more importance and demand for constant valuation of the role played by the generators of scientific-technological knowledge - research institutions and universities. In an internationalized world where commercial boundaries are left behind by virtue of multilateral agreements, support for the production of new knowledge and priority given to collective apprenticeship are sine qua non conditions for the sustainable development of a nation in a new worldwide economical system. The relations between the State and scientific-technological organizations have to be strengthened and permeated by ethical values and moral commitments.
\end{abstract}

Production of knowledge is a complex and difficult task demanding time and dedication besides well-equipped laboratories and the necessary financial resources for their maintenance. The knowledge to be produced should be aimed to meet the needs of society and improve the life quality of our populations. Thus, a task that has to be part of the agenda and be supported by the national social, scientific, technological and industrial policies, which should be harmoniously engaged in short- and long-term strategies for the welfare of the nation.

The development of science and technology requires patience - research in the field of human health can take years to produce results. Besides carrying out the research activities itself, institutions and universities have to observe the rigorous regulations for the approval of products of the

Fax: +55-21-590.3495

E-mail: egarcia@gene.dbbm.fiocruz.br

Received 7 August 2000

Accepted 4 September 2000
National Agency for Sanitary Surveillance. The improvement of science and technology requires commitment and continuity - scientific investigation carried out in public institutions cannot be vulnerable, cannot be subject to changes in the conduct of policies and lack of budgetary commitment. The development of science and technology requires consistency, dedication and seriousness.

The establishment of a policy valuing scientifictechnological activity is of highest relevance. Such a policy should contemplate the health conditions of the people, respect life, consider ethical-humanitarian principals in inter-institutional relations and ban authoritarian attitudes uncommitted with human relationship. They should preserve the right to free opinion, to a healthy co-existence of opposed points of view and different levels of power.

To provide conditions for scientific-technological production in public institutions is a duty of the State. We all, scientists and technologists, are responsible for the future of our country. We all should fight for the maintenance and improvement of our scientific and technological institutions for it is their existence that grants the development of products meeting the demands, especially of our most needy people. Private enterprise obviously develops activities aimed at profitable returns. Thus, food products, habitation technologies, public health, sanitation and production of essential drugs for the needy communities are not necessarily among its priorities. To invest in these activities is a duty of the State. The public institutions involved with science and technology have to be aware of their responsibility to act, regulate and legislate, respecting human life. And society has to charge them in case of failure or omission. Each citizen has this right.

Globalization and the tendency to privatization notwithstanding, we have to preserve our pride and respect for the national organizations, for what they have done and for what they are doing. We cannot let go hold of our sense of social justice and individual personal dignity. We cannot let fall to ruins the knowledge already constructed. On the contrary, we have to amplify and strengthen it. Misery can only be fought with much work, with de- 
mocracy and heavy investments in education, health, research and development, by destroying ignorance, building intelligence, technological capacity and productivity.

We live in an age in which the power of science becomes evident every day. A better quality of life, the advancements in medicine and public health have doubtlessly contributed to an increase in the life expectancy in Brazil. Fifty years ago, the major part of Brazilians born at that time had a life expectancy of less than 45 years. Today, the expectancy of life in Brazil is about 64 years and will probably be more than 70 years in 2020 unless pandemic diseases such as Aids reverse this picture. Although science and technology helped to relieve the situation, diseases known for a long time are still killing the poor and deprived. We have to deal with diseases of a society suffering from problems typical for the developed countries such as cerebrovascular and heart diseases, environmental violence, diseases of the third age, diabetes, among others. At the same time we still have populations ravaged by the most different diseases related to poverty: malaria, dengue fever, leishmaniasis, yellow fever, Chagas disease, schistosomiasis, filariasis, cholera and viral diarrheas. We only have to read the newspapers every day to learn about the incidence of these diseases, the appearance of new ones such as Aids and the reemergence of others as in the case of tuberculosis. We specially learn about diseases specific for the developing countries where we have people living in nearly uninhabitable environments. The health sector whose strategies during the last 20 years were based on equality and the premise "health for all" witnessed an increase of disparities to be seen with the naked eye. We cannot live well knowing that $1 / 5$ of the planet's population enjoys wealthy while poverty is threatening the remaining $4 / 5$. Absolute misery is increasing and already affects 1 billion of individuals.

To reverse this picture we have to invest in new drugs, vaccines and therapies for the control and eradication of endemic diseases, typical for the poor countries. The necessary funding, however, should not only come from the public sector. The national private industry has also to invest in this area. We have to make optimal use of our rich biodiversity and of the knowledge created by the scientists of universities and research institutions. Research and technological development should be a joint effort of universities, research centers and private enterprise. There is a great range of modalities: joint ventures, agreements, technological pools and so forth. To wait exclusively for technology transfer from the developed countries signifies to deepen the existing crisis, even in the era of globalization.
It is extremely difficult for the developing countries to gain access to new health technologies privatized by great multinational corporations, among others involved with certain high technology sectors - genetic engineering techniques for the production of vaccines for example - extensively protected by industrial property rights.

The exploration of our genetic patrimony could be the solution in the near future for the most different public health problems. Explore means to map the genetic resources, study them, know their properties and applications and use them in a scientific, rational and equilibrated way. First, however, we have to create conditions for a better utilization of this relative advantage - our megabiodiversity - establishing a policy for regulating the access to and the use of these resources.

Biotechnological research developed extraordinarily during the last ten years. Research on the genome of plants, microorganisms and animals, use of fungi with therapeutic action, recombinant DNA technology, improvement of ex situ conservation techniques for biological material, cloning of plants and animals. There is a great number of possibilities for a commercial exploration not only of our biodiversity but also of the knowledge of the indigenous populations about use and preservation of species. Only this way, abuse resulting in destruction of the tropical forests can be avoided. It is absolutely necessary to amplify the debates involving all interested sectors: the academic world, private enterprise, the government, scientific societies, non-governmental organisms, politicians, the media and society at large.

On the other hand, it is necessary to encourage the formation of human resources for the study of the Brazilian fauna and flora. The country lacks more researchers dedicated to the study of new medicaments. More financial resources for the purchase of equipment, construction of new laboratories, especially for the screening of medicinal plants and natural products, and for the reform of old installations adapting them to the new quality and biosafety requirements are necessary.

Joint ventures between research institutions, the industry and universities on national and international level should be increasingly encouraged and supported. Globalization and the new forms of competition demand from the agents involved in the process of creation and dissemination of technologies continuous efforts towards an increase in the innovation capacity. The international example shows us the importance of developing joint scientific-technological projects. Strategic agreements are fundamental for the creation of new products and/or processes besides being one of the mechanisms for advantageous competition. Partnerships 
favor the access to knowledge and techniques and allow following the technological progress, in the case of biotechnology extremely accelerated. Cooperative practices represent an efficient mechanism for reducing the high costs, risks and uncertainties of research and development activities, obstacles for the development of technologies. Other advantages are the interchange of experience among highly qualified professionals and the possibility of sharing installations and equipment.

Besides, scientific-technological institutions have always to be attentive to the projects developed by their researchers, not only in the country but also abroad. Innovative projects should be evaluated with respect to their patentability. Unlawful seizure of research carried out with national genetic and financial resources cannot be tolerated anymore. The institutions should develop policies establishing guidelines for the patenting of inventions. Our universities and research institutions are presently in a rather difficult situation, principally as refers to salaries and financial resources for research. The government suggests administrative reformulation with emphasis to the obtainment of own resources. One of the alternatives in this case is the licensing of patent rights.

Never before science had so many potential applications to public health and medicine. Applied science seems to be the hit, but we must not forget the fundamental role of basic research. Today, any policy restraining basic research seems to me as irresponsible as the repression of basic research at the times of Galileo, little before the Newtonian revolution. To invest in basic research means to invest in new ideas, new solutions, and new knowledge and in the continuity of science itself.

It is also necessary to strengthen and amplify the national institutions funding technological development. Research activity requires constant financial support and time, given that results cannot be obtained quickly. Today we count on national agencies of highest relevance: Banco Nacional de Desenvolvimento Econômico e Social (BNDES), Financiadora de Estudos e Projetos (Finep), Programa de Apoio ao Desenvolvimento Científico e Tecnológico (PADCT) (in part under coordination of Finep), Conselho Nacional de Desenvolvimento Científico e Tecnológico (CNPq), Coordenação de Apoio ao Pessoal do Ensino Superior (Capes), and the Programa de Recursos Humanos em Áreas Estratégicas (RHAE) and Coordenação Brasil- Argentina de Biotecnologia (CABBIO), programs of the Ministry of Science and Technology. Anyhow, it is necessary to establish a policy for health-applied biotechnology cre- ating special programs for the development of new drugs, vaccines and diagnostic kits allowing a much more directed allocation of funds, better utilization and better chances to create new products and processes. Another point to be emphasized is the need to amplify the mechanisms for obtaining venture capital, fundamental for the establishment of companies and biotechnological cooperation programs. Risk capital invested in research is part of a development strategy. Such investments have surely nothing to do with speculative undertakings, which due to their nature are likely to cause considerable losses at any moment.

To find the solution for the Brazilian public health problem is not simple or easy. Adequate management of technology is only one aspect of this complex matter but it would represent a big step on the way. We all know that health is a priority, and we all should join efforts to relieve the situation. Health is a right of the citizen; despite of being somewhat banalized today. The government has thus a great responsibility. Strong efforts will be necessary for providing wellbeing, better quality of life and full access to preventive measures and treatment of the different harms annoying the Brazilian society.

Brazil's participation in the new international economical conjuncture depends basically on the support given to technological innovation and cooperation practices, on the national technological capacity building and on encouraging competitiveness. The future of the country depends on efficient official policies capable of administrating and distributing financial, technological and human resources in benefit of the entire society.

The public agents involved in the adaptation process to the new times will have to employ great efforts for minimizing the technology gap and improving the level of technological and administrative capacitation. The intensification of technological development will stimulate our economic growth, and in consequence result in major working opportunities.

The challenge for the construction of a new Brazil lies thus in accepting the deficiencies of the present structure and in recognizing the importance of technological development in its new competitive context.

To enter in the developed world means to leave mere rhetoric behind and go on to practice. However, it will take courage and determination to make those accustomed to easy and quick profit invest in medium and long-term perspectives without immediate returns but with the intent to invest in the future of a nation. 